


\section{DISCLAIMER}

This report was prepared as an account of work sponsored by an agency of the United States Government. Neither the United States Government nor any agency Thereof, nor any of their employees, makes any warranty, express or implied, or assumes any legal liability or responsibility for the accuracy, completeness, or usefulness of any information, apparatus, product, or process disclosed, or represents that its use would not infringe privately owned rights. Reference herein to any specific commercial product, process, or service by trade name, trademark, manufacturer, or otherwise does not necessarily constitute or imply its endorsement, recommendation, or favoring by the United States Government or any agency thereof. The views and opinions of authors expressed herein do not necessarily state or reflect those of the United States Government or any agency thereof. 


\section{DISCLAIMER}

Portions of this document may be illegible in electronic image products. Images are produced from the best available original document. 


\title{
Systems Analysis Guide For The Rare-Earth Information \\ Center's Information Retrieval System (RICIRS) \\ By
}

Leonard C. Moon

\begin{abstract}
Ames Laboratory, ERDA
Iowa State University

Ames, Iowa 50011
\end{abstract}

Date Transmitted: April 1977

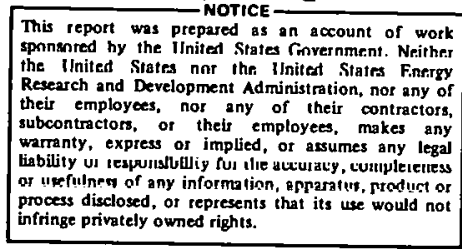

process disclosed, ot represents
infringe privately owned rights.

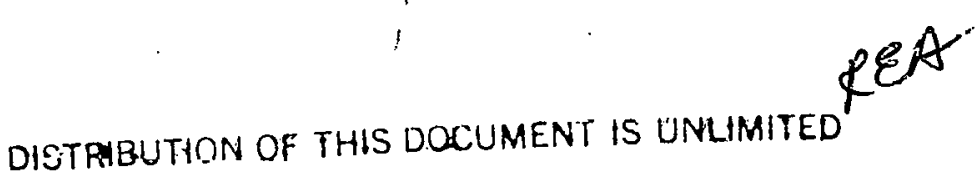


This report wae propared as an account of work sponsored by the United States Government. Neither the United States nor the United States Energy Research and Development Administration, nor any of their employees, nor any of their contractors, subcontractors, or their employees, makes any warranty, express or implied, or assumes any legal liability or responsibility for the accuracy, completeness, or usefulness of any information, apparatus, product or process disclosed, or represents that its use would not infringe privately owned rights.

Available from: National Terhnical Information Service U. S. Department of Commerce P.O. Box 1553

Springfield, VA 22161

$\begin{array}{ll}\text { Price: } & \text { Microfiche } \\ \text { Paper Copy } & \$ 3.00\end{array}$ 
TABLE OF CONTENTS

$\begin{array}{lr} & \text { PAGE } \\ \text { ABSTRACT } & \text { iv } \\ \text { INTRODUCTION } & 1 \\ \text { CONSTRUCTION OF THE DATA BASES } & 2 \\ \text { RETRIEVAL PROCESS } & 9 \\ \text { PRESENT CAPABILITIES } & 17 \\ \text { POSSIBLE FUTURE EXTENSIONS } & 18 \\ \text { ACKINOWLEDGERTHTS } & 19 \\ \text { REFERENCES } \quad \text { JCL DECKS FOR BOTH THE RICIRS AND THE } & 20 \\ \text { APPENDIX A: INFORMATION RETRIEVAL SYSTEMS } & 21 \\ \text { APPENDIX B: RICIRS FLOWCHART } & 37\end{array}$


The Rare-Earth Information Center Information Retrieval System (RICIRS) is a system of programs written in $\mathrm{PL} / 1$ and compiled by the PL/I optimizing compiler for an IBM 360-370 environment. It is a key word based retrospective information retrieval system. Conference papers, journal articles, books, and other bibliographic material are abstracted by the Rare-Earth Information Center personnel and placed in the data base.

This report details the programs and their operation with respect to the files built by the Rare-Earth Information Center personnel. It is intended to be a guide for a programmer-analyst to maintaining and upgrading the system. 
Distribution List:

Chicago Patent office 1

USERDA-TIC

27

Ames Laboratory Library

Leonard C. Moon

15

Tota1

48 


\section{Introduction}

RICIRS is an acronym which stands for Rare-Earth Information Center Information Retrieval System. It is a key word based retrospective information retrieval system designed to retrieve blbliographic information that has been abstracted from conference papers, journal articles, books, and other bibliographic material. The bibliographic material is abstracted by the Rare-Earth Information Center personnel. They extract the key words which will be used to rcericve tho document and put these key words alnng with the rest of the bibliographic information for the document into the data files so the RICIRS system can access the document.

This report is intended to be used by the programmer-analyst as a guide to maintaining and upgrading the system. It contains three main parts. The first part describes how the data bases are constructed. The second part describes the retrieval process. The third part lists present capabilities, problem areas and possible future expansions.

RICIRS is a spin-off of the Selective Dissemination of Information (SDI) system developed at the Iowa State University Computation Center by James Hoekstra and Nancee Nilsen (4). They adopted many of the ideas incorporated into the SDI system from an earlier SDI system developed by John Jordan and Rowena Sun $(1,2,3)$. 
I. Construction of the Data Bases

There are four programs which create files in the system. They are: UPDATE, CITN, TERM, and DUM. UPDATE modifies the master weekly and master monthly files by adding, deleting, and replacing cards and wiping out entire documents on the raw (sorted by document number) bibliographic data (card) files.

There are four types of cards that can be added to the raw data (master) file. They are:

1. Author

2. Title

3. Source

4. Key Word

Each card type can be continued up to nine cards. This means the overall maximum for a document would be 36 cards, but in practice is between 7 and 12 cards. A more complete description of the updating process can be found in Operation and Maintenance of the Rare-Earth Information Center's Information Retrieval System (RICIRS) Version 2 (5).

CITN takes the edited raw bibliographic data files and produces two other files; a citation file which represents much of the raw bibliographic data and a word file which has ali of the key words and authors associated with the document, in ordered pairs (document number, key word or author). These ordered pairs are sorted by document number within key word and used as input to the TERM program. The I'ERM program builds a variable length record for each key word (or author). 
This record appears as follows:

\begin{tabular}{|l|l|l|l|l|}
\hline KEY WORD & Document No. 1 & Document No. 2 & Document No. $\mathrm{n}$ \\
\hline
\end{tabular}

where all document numbers are in ascending order, Document No. $1<$ Document No. $2<$ Document No. n .

The program DUM creates dummy weekly files. It is only run with the monthly update procedure: These dummy files are needed for the successful running of the retrieval program.

'Iwo ocher progralls aile uset in the file oroating proress. The SORT/MERGE utility package and a listing program, PRINTEM. The SORT/MERGE package is used because al1 files are sorted for ease of handing when creating the files and retrieving information. PRINTEM accesses the term file (produced by TERM) and prints the authors and key words with their associated number of documents.

Figures 1 and 2 show the necessary steps for the updating of the weekly and monthly files: 


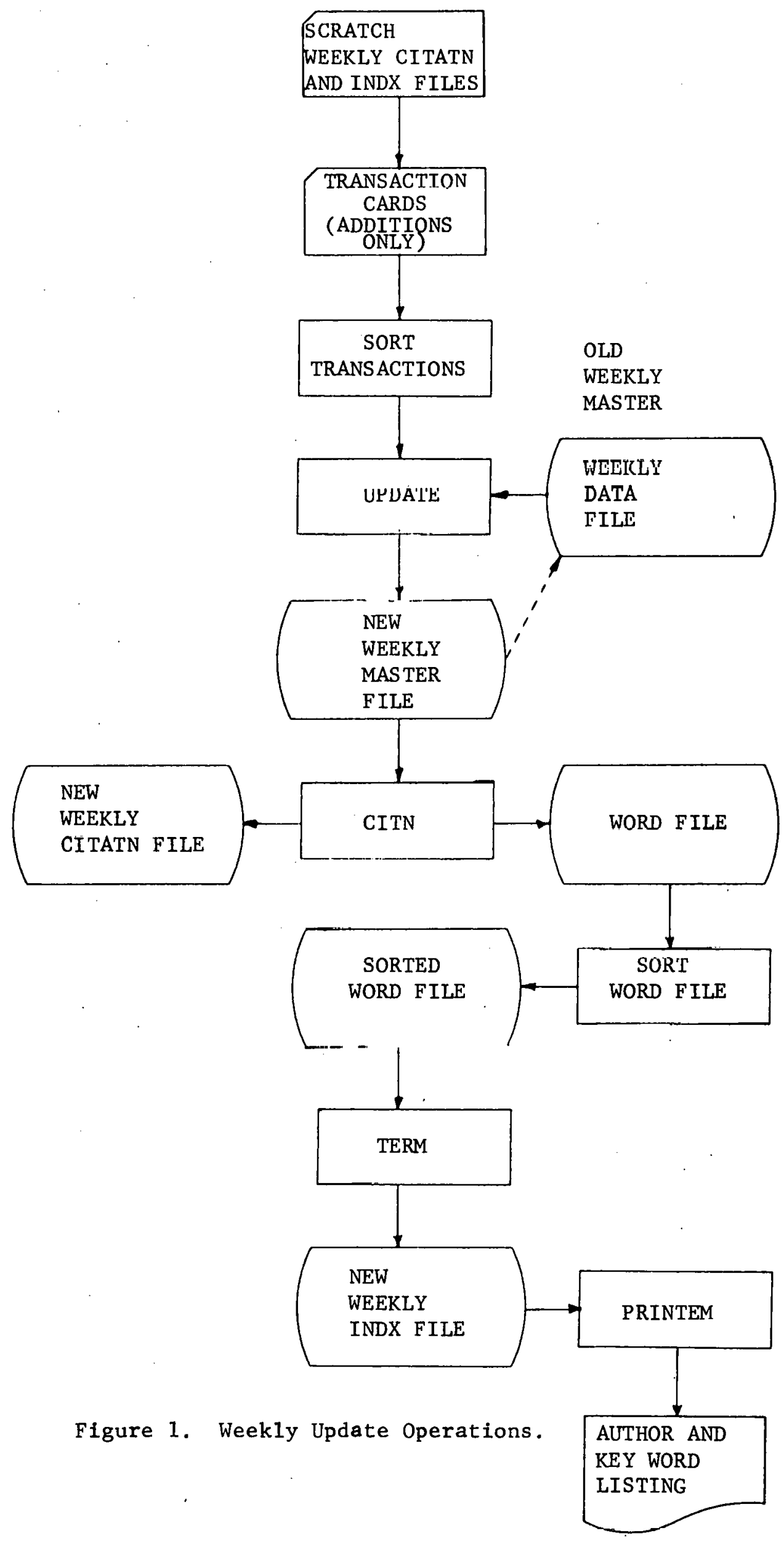




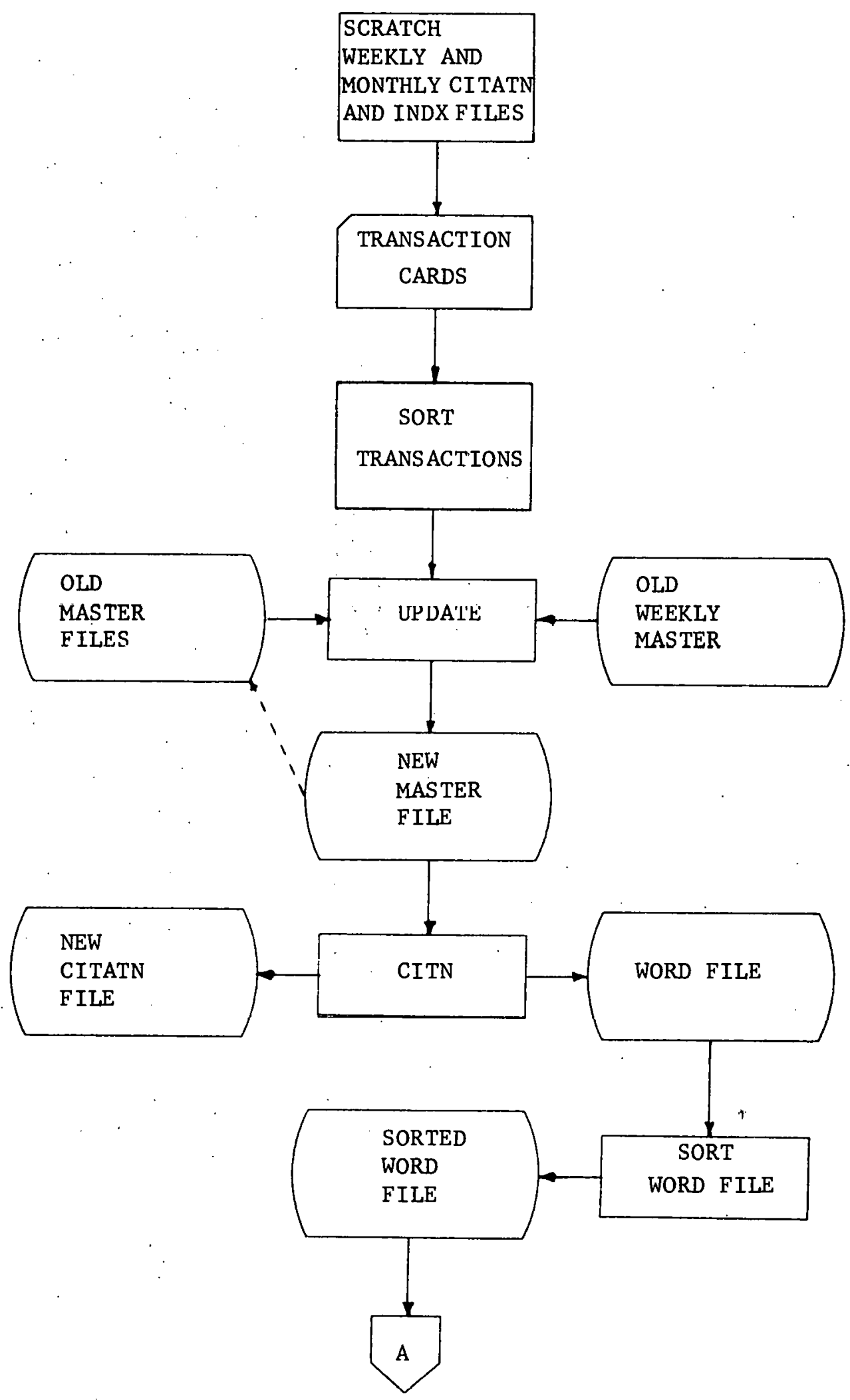

Figure 2. Month1y Update Operations. 


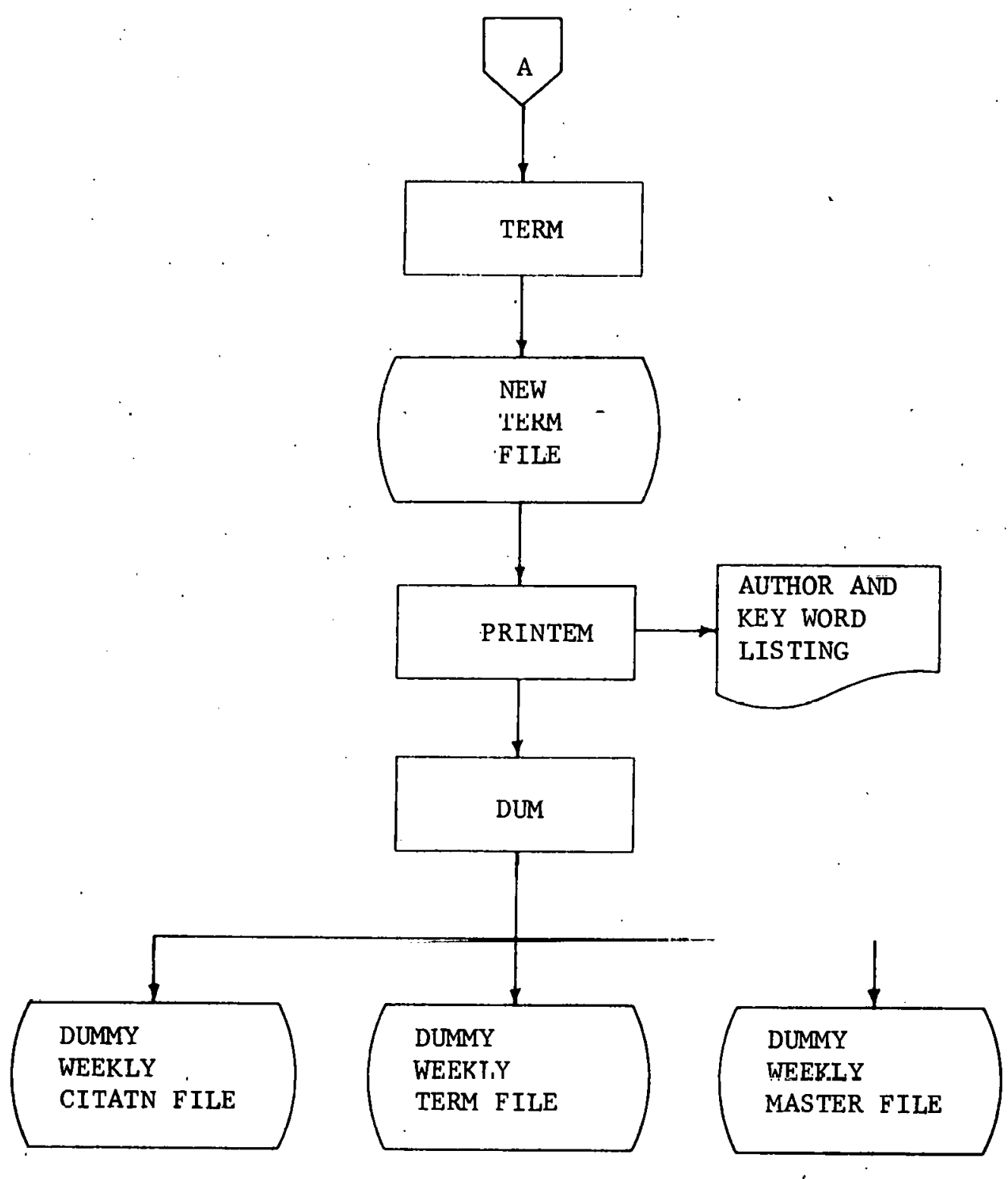

F1gure 2. Monthly Update Operation (Continued). 
The citation files (CITATN and CITWK) are index sequential files using the document number as the index key. These files are basically the raw document coding with added information needed for document retrieval and printing. They are variable blocked files with a record length of 914 and a block size of 7246 . These files were set up to be used on a 2314 disk pack, if another type of pack is used, modification of the blocking factor at least should be considered. The record length allows an entire document to be written and read in one operation if that document is less than titteen cards in lēngth. The structure used for the citation files consists of 2 characters for the status of the document (presently unused), 2 characters for filler (unused), 1 character representing the number of author records, 1 character representing the number of key word records, 3 characters representing the document number, and 15 sixty character descriptors representing the bibliographic data. The sixty characters are taken from the first sixty columns on the raw document cards.

\begin{tabular}{|l|l|l|l|l|l|l|}
\hline Length & $\begin{array}{l}\text { Initial Document } \\
\text { InIolmation }\end{array}$ & $\begin{array}{l}\text { Document Card } \\
\text { Information } 1 \text { 1 } 1\end{array}$ & 非 & \#3 3 & $\ldots .$. & \#15 \\
\hline
\end{tabular}

The term files (INDX and INDXWK) are index sequential files using the key word (author or key word) as the index key. These files are built from the document number, key word or author ordered pairs produced by the CITN program. The TERM program simply takes all of the document numbers associated with the key word and places them in ascending sorted order behind the key word in a variable length record. The file is 
variable blocked with a record length of 7230 and block size of 7234 . The records are as follows:

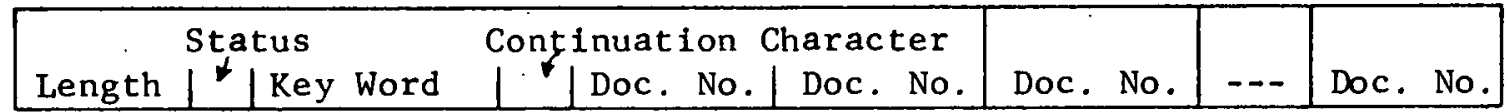

With this structure 2403 documents can be held on a 2314 disk track. 
II. Retrieva1 Process

The user supplies a request which is a boolean statement. The request consists of three types of cards:

1. a parameter card,

2. a boolean statement of the retrieval request,

3. a limit on the number of citations desired-user ID card.

Only one type 1 card is needed per run of the retrieval program and any number ( 1 to $N$ ) of type 2 and 3 as long as there is a type 3 for every set of type 2 cards.

A parameter card has six 6 character fields starting from the left. These fields from left to right are:

1. maximum sort array area,

2. area within the sort array devoted to the merging process, this should be approximately $20 \%$ of the size of the sort area in the sort array, e.g., if maximum sort array area is 12000 then this should be 2000 ,

3. the initial index of the sort array area (can be any integer value between $-32 \mathrm{~K}$ and $+32 \mathrm{~K}$ ),

4. first yearly stratifier, only documents meeting this qualiflcatlun will be put into the sort array, $75 \rightarrow$ only documents from 1975 will be placed in the sort area,

5. second yearly stratifier, if left blank it takes on the value of the first yearly stratifier,

6. If the sixth field is non-blank the program assumes that the user wants author and key word indexes generated and the appropriate files are generated.

NOTE: All but the sixth field must be right justified. 
An example of a parameter card that would generate the flowchart shown in Figure 3 is:

\section{6}

This would mean the sort array area would be 12000 words in length with 2000 words of it devoted to the merging process. The initial index is 1 of the sort array area. All documents in the sort array area would be from the 1960's or 1970's.

An example of a parameter card that would generate the flowchart shown In Figure 4 is:

664000612000-32000\$\$67566567666XRFF 


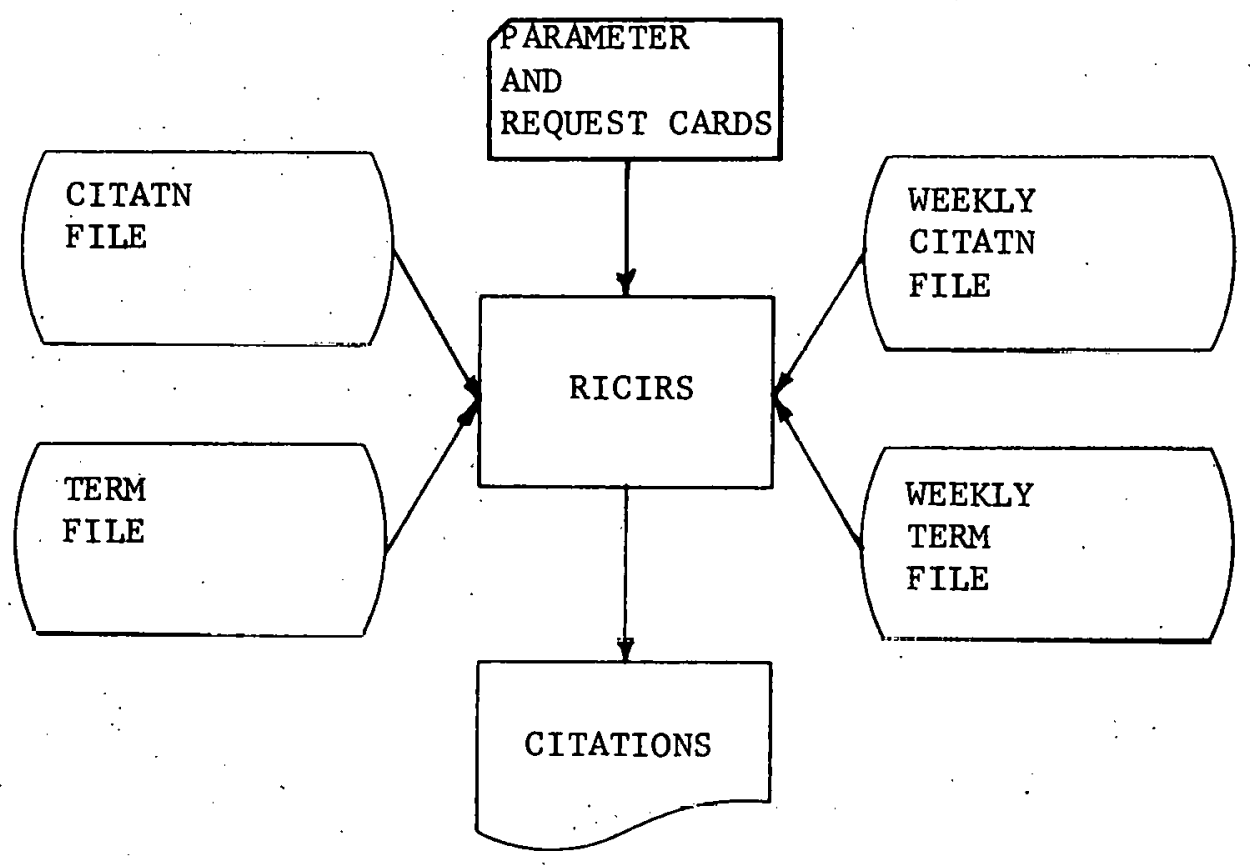

Figure 3. Retrieval Program Without Author and Key Word Listings. 


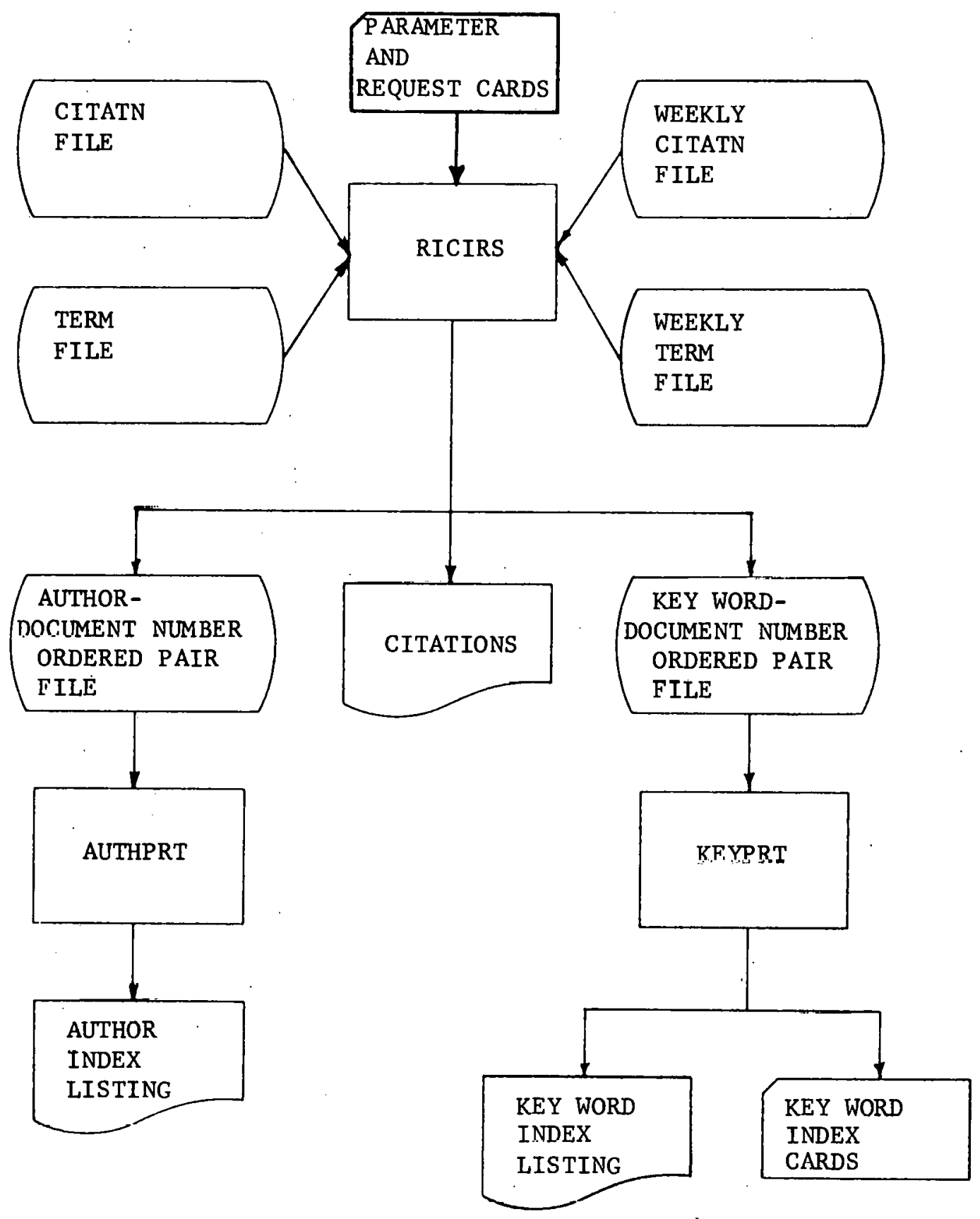

Figure 4. Retrieval Program With Author and Key Word Listings. 
In this example the maximum sort array area is 64000 words and the merging area is 12000 words. The initial index is -32000 . Only documents from 1975 and 1976 will be placed in the sort array area. An author and key word index will be generated.

The limits of the sort array area are $64 \mathrm{~K}$ in length and $32 \mathrm{~K}$ on either side of zero, therefore to get the $64 \mathrm{~K}$ desired we must specify the initial index as $-32 \mathrm{~K}$. Each document that meets the yearly stratification takes 1 word of storage in the sort array area.

The second type of caid in tie retrieval proococ ie the boolean statement of the request. This is a mixture of operands (key words and authors) and the boolean operators * (AND), $+(\mathrm{OR})$, and $\rightarrow(\mathrm{NOT})$. Every operand and operator must be separated by at least one blank. Parentheses may be used as desired.

Examples of request statements:

1. $A * \neg(B+C)$

2. $A * B+C$

3. $A+(B * C)$

4. ᄀ $\mathbf{A}$

In the first example, A must be present but B or $C$ (or both) ${ }^{l}$ can not be present for the program to print-out the document. In the second example, either $A$ and $B$ must be present or $C$ (or both) for the document

$1_{\text {The OR }(t)}$ is the "inclusive" OR. It is true when either or both of the operands is true. 
to be printed. In the third example, either $B$ and $C$ or $A$ (or both) must be present for the document to be printed. The fourth example is an invalid case for the program. The $\neg$ condition must be preceded by $*$, so it becomes $* \neg$ (AND NOT) and is therefore a binary instead of a unary operator.

The program recognizes four special cases (types) of requests and works much faster (cheaper) if the request is of one of the four forms. They are:

1. Operands connected by a11 't's, e.g., $A+B+C+D+\ldots$.

2. Operand 1 and-ed to a set of operands connected by ' + 's, e.g., $A *(B+C+D+E+\ldots)$.

3. The set operand 1 OR'ed with operand 2 and then and-ed with

a set of speidal cumneled by ' $t$ 's,

e.g., $(A+B)$ a $(C+D+E+\ldots)$.

4. Each pair of operands and-ed together and all pairs connected hy ' + 's, $P . g$, $(A * B)+(C * D)+(E * F)+\ldots$.

There are some limitations on the requests.

They are:

1. Each request begins on a new card.

2. A singie request must be contained on no more than five cards.

3. The total number of terms, operators, and parentheses in a request must not exceed 100. 
A feature is available which allows a match to occur on a leading substring of a term. When the symbol '非' is the last character of a term the program matches any term in the file which begins with the string preceding the '非'. For example, "MAGNET非" will cause a match on MAGNET, MAGNETIC, MAGNETIC-SUSCEP, etc.

NOTE: If the request ends in column 80 of the card, another blank card must be added to the request deck for the program to work properly. Also, multiple requests are not allowed when the author and key word indexes are desired.

The third type of card is the request-ID card. It is composed of four fields. Example:

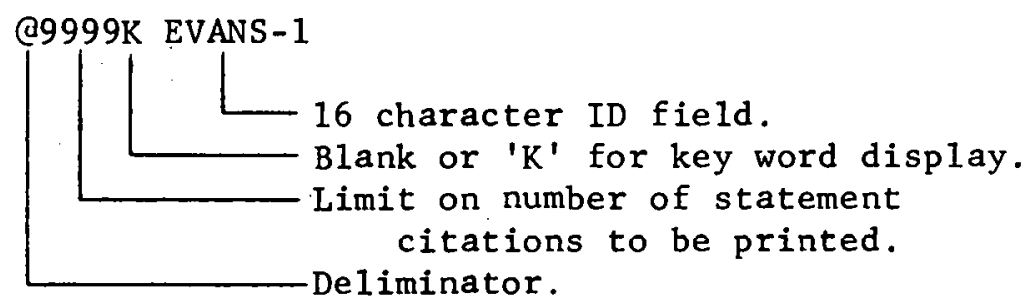

If the limit field is set to 8888 the program only lists out the number of documents for each term in the request. No evaluation of the request is done and no citations are printed. If the user wants the key words associated with each document the area on the request-ID card for this must have a " $K$ " in it.

The retrieval program (RICIRS) first analyzes the boolean request string and changes it into a "POLISH" string for ease of operation. It then takes each term (author or key word) and searches the INDX and INDXWK files for the term. If the term is found the 7 character 
document numbers associated with this term are brought in and checked to see if they meet the yearly stratification criteria. If they meet the yearly stratification criteria, the position within the "POTISH" string of the term is merged into the document number and this number is then placed in the sort array area. This process of looking up the terms is continued until the "POLISH" string is crhauctod.

The documents associated with their position in the "POLISH" string are now sorted and the evaluation process begins. The type of the request is determined to facilitate faster handling of the documents. For example, if our request is of type $2, A *(B+C+D+\ldots)$ then all we have to do is check those document numbers associated with $A$ to see if there is a B or C or D or ... associated with it. Also as soon as the document number is found to be true e.g., A* B true, then the document number can be used to get the citation off of the citation file. The entire string need not be searched everytime with special cases. The other special cases have similar algorithms to evaluate the documents appropriateness. 


\section{Present Capabilities}

The RICIRS data base contains approximately 11,000 documents from 1900 to the present, with approximately 10,000 authors represented and 7,500 different key words. The cost for a "typical" request is $\$ 1.25$ to $\$ 1.75$. The cost for a monthly update is about $\$ 25.00$ and the cost of a weekly update is about $\$ 3.00$. Of course, a11 of these costs are dependent on the amount of cards input and the amount of lines output since the computation center charges directly for these items.

The disk (2314) is about half full so it should be able to hold at least another 10,000 documents before another disk would need to be purchased. At present rate of updating this will probably be at least four years from now. More space could be obtained by placing the master card file on magnetic tape. At present this would yield approximately 40 cylinders of space on the disk.

The RICIRS system has also been modified for use with the dust explosion bibliograph data the Ames Laboratory has been collecting. This data base has about 1000 documents from 1882 to the present. The RICIRS system was modified for the grain dust explosion project (6). This system contains approximately 1000 documents from 1882 to the present, with approximately 1000 authors and 200 key words. 
IV. Possible Future Extensions

At present both the weekly and monthly files are generated in the same way. That is, the citation and term files are destroyed (scratched) and are entirely recreated from either the master monthly or master weekly card files. The weekly files were designed to make it easier and less expensive to update the data base. Possibly a random update scheme for the weekly data base would be much less expensive than the present destroy and re-create scheme used. This random scheme might also make it more convenient to use (1ess JCL for the user to deal with). This might make the data base more of a current awareness data base than it is at present. To go to a random scheme CITN, TERM and RICIRS would have to be changed in the way they access the files. 


\section{Acknowledgements}

This work was supported by the U.S. Energy Research and Development Administration Division of Physical Research.

Thanks are due to James Hoekstra and Nancee Nilsen for their expert help during the modification of their program system. Special thanks are due to Wanda Lembke for her typing assistance and patience during the final stages of this report. 
VI. References

1. Jordan, J. R., Sun, R. P., and Maple, C. G., "A Description of a Batch Operated Retrospective Information Retrieval System", USAEC Report IS-3387, 1974.

2. Jordan, J. R., Sun, R. P., and Maple, C. G., "Data Base Design Considerations for a Key Word Based Retrospective Information Retrieval System", USAEC Report IS-3389, 1974.

3. Jordan, J. R., Sun, R. P., and Maple, C. G., "Operation and Maintenance of the RARE-EARTH Information Center's Information Retrieval System (RICIRS)", USAEC Report IS-3388, 1974.

4. The SDI Retrospective Literature Search System, ISU Computation Center, Users Reference Memo 033.

5. Moon, L. C., "Operation and Maintenance of the Rare-Earth Information Retrieval System (RICIRS) Version 2", USERDA Report IS $-4104,1977$.

6. Verkade, M., and Chiotti, P., "Bibliography of Grain Dust Fire and Explosion", Project 400-25-04, IS-EMMRI-5, 1976. 
$\underline{\text { RICIRS Retrieval Deck }}$

/ $/ B 393 L N$ JOE AO129, MCON

$1 / \mathrm{JCEL} I B$ DD DSN=RIC.PROG.VOL =SFR=RICIRS,UNIT=2314.DISP=SHR

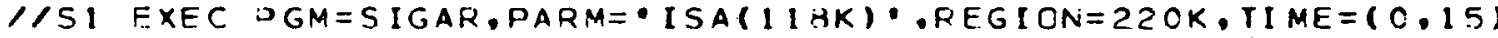

$1 /$ SYSPRINT DD SYSOUT=A. DCE =(RECFN=VBA, LFECL=137, ELKSIZE=141)

ICITWK DO UNIT $=2314 . D I S P=S H R . D S N=R I C . C I T \cdot W E E K$.

$1 /$ $D C B=(C S O R G=I S \cdot B U F N O=1) \cdot V O L=S E R=R I C I R S$

$1 / I N D X W K$ DO UNIT=2314,DISP=SHR,DSN=RIC.TERM. WEEK.

I. $D C .3=(D S O R G=I S, B U F N O=1), V O L=S E R=R I C I F S$

IINDX DD OSN=RIC.TERM. NEW,DCB=(DSORG=IS,BUFNO=1).UNIT=2314.

I/ VOL $=S E R=R I C I R S, \cap I S P=5 H R$

I/CITATN DO USN=RIC.CIT.NEW, DCB=(DSORG=IS, EUFNC =1), UAIT=2314.

/ VOL $=S E R=R I C I R S, D I S P=J H R$

I/L IERPT: DO SYSOUT=A

I/USERPRT DC SYSOUT=A

$/ / P L I O U M J D D$ SYSOUT=A,DEB=(RECFM=VRA.LRECL=137, ELKSIZE=141, BUFNC=1)

I AREOUEST DO *

120002000

$(L A+L A-) *(P R+P R-)$

ล. $0001 \mathrm{KBE}-3$ 
I/B 38 3LM JOE AO129.NOON

$1 / J O B L I B$ OD ISSN=RIC.PROG.VOL=SER=RICIRS,UNIT=2314, IISP=SHZ

//SI EXEC PGM=SIGAK,PARM= ISA (IIBK) , REGION=22CK, TIME=(0.15)

IISYSPRINT OD SYSOUT=A, DCB=(RECFN=VBA.LFECL=137, ELKSIZE=14I)

$\angle / C I T W K$ DD UNIT $=2314 \cdot D I S P=S H R, D S N=R I C$. CIT WEEK .

$1 / D C B=(D S O R G=I S, B U F N D=1), V D L=S E F=R I C I R S$

IIINOXWK DO UNIT $=2314.0$ ISP=SHR, DSN=RIC. TERN. .WEEK,

$/ / O C B=(O S D R G=[S, B U F N O=1), V O L=S E R=R I C I R S$

$/ / I N D X$ DD DSN=FIC.TFRM.NFW.DCB=(DSORG=IS, BUFNO=1),$U N I T=23140$

// VOL $=S E R=R I C I R S, D I S P=S H H$

I/CITATN DD DSN=RIC.CIT .NEW,DCH=(CSORG=IS, BUFNC=1), UNIT=23:4.

$/ / V O L=S E R=R I C I R S . D I S P=S H R$

$\angle / L I B R P T R$ DD SYSOUT=A

$\angle U S E R P R T$ DD $S Y \subseteq O U T=A$

/ /PLIDUAP DD SYSCUT=A,DCB =(RECF $=V A A,-R E C L=137, E L K S I Z E=14 \% . B U F N O=1)$

IIREQUFST DO *

12002 2000 1 XREF

ล9990K3E-1

/ /AUTHOR DD DSN=E,EAUTH,DISP=(NEN,PASS , VCL=SER=SHCRT1.UPI

$1 / D C B=(R E C F M=F E, L R E C L=24$. BLKSIIE $=180 D$. BUFNO=1),

$1 /$ SPACE $=(T R K,(1.1))$

/ /KEYWORO DD DSN=E\&KEY, OISP=(NEN,PASSI, UNIT=SCRTCF,

/ $O C B=(R E C F M=F E, L R E C L=19, B L K S I Z E=1805, B U F N D=1)$,

$1 /$ SPACE $=(T R K,(\geq .2))$

//S2 EXEC PGM=ALTHPRT, PARN= ISA:4K) , PEGICN=48K

I/OUT DD SYSOUT=A

/ /PLI DUMP DD SYSUUT=A

I/SYSPRINT DO SYSOUT=A

//SORTIN DD DSN=EEAUTH, DISP=(OLD, DELE-F), VOL=SEF=SHORTI, UNIT=2314,

$1 / C C B=(R E C F M=F B, L R E C L=24,3 L K S I E E=1800)$

I/SYSOUT DO SYSCUT $=A$

//SORTL IB DD DI ISP=SHR, DSN=SYSI. SCRTLIE

$/ /$ SORTWKOI DO UNIT 1 SCRTCH.SPACE $=(T R R,(30)$, CONTIG)

$1 /$ SORTWKO2 DD UNIT $=$ SCRTCH.SPACE $=(T R K,(30)$, CONTIG)

$1 /$ SORTWKO 3 DD UNIT $=S C R T C H$, SPACE $=(T R H,(30)$, CONTIG) 
RICIRS Retrieval Deck with Author and Key Word Indexes (Continced)

/ ISURTOUT DD OSN=EETEMP.DISP=(NEW . DELETE), UNIT=SCRT CH.

I) SPACE $=(T K K,(1,1)), D C B=(R E C F M=F B, L R E C L=24, B L K S I Z E=1800)$

//S.3 EXEC PGM=KEYPRT, PAPM = ISA(O4K). NR • REGICN=48K

I/SYSPRINT OD SYSOUT=A

$\angle / C U T$ DO SYSOUT $=A$

/ OUUTCARC DO SYSQUT=B

/ /SORTIN DD DSN=EEKEY, DISP= (CLD. DELETE), UNIT=SCRTCH,

I/ $D C B=$ (RECFM $=F E$. LRECL $=19$. BLKSI ZE=180S)

/ ISORTOUT DD DSA=EETENP2, DISF=(NEW.DELETE), UNIT=SCRTEH.

1/ SPACE $=(T R K,(3.2)), O C B=(R E C F M=F E \cdot L R E C L=19, B L K S I Z F=18 C 5)$

IISYSOUT DN SYSCUT=A

/ ISCRTLIB DD DISP=SHR.DSN=SYSI :SCFTLIE

$/ / S U R T W K O I$ DO UNIT=SCRTCH.SPACE $=(T R K,(30),, C C N T I G)$

$1 /$ SORTWKO2 DO UNIT=SCRTCH.SPACE $=(T R K \cdot(30)$, CONTIG )

$1 /$ SORTWKO3 DC UNIT SSRTCH.SPACE $=(T R K \cdot(30)$, CONTIG $)$ 


\section{Weekly Update for RICIRS}

/ A245GSUP JOB AO129.EVANS, MSGLEVEL $=(1,1)$

* JCBPARN LINES $=30$

$/ / J C B L I B$ DD DSN=RIC.PROG, UNIT=2314,VOL=SER=FICIRS,OISP=SHR

$1 / S C$ EXEC PGM=IEFBRI4, REGION=32K

$/ / D 03$ DD OISP=(CLD,DELETE), UNIT=2314,VCL=SER=SFCFTI,DSN=RIC.WORD

$1 / 004$ DO DSN=FIC.SORTWD.VOL=SER=SHORT 1. UNIT=2314.CISP=(OLD,DELETE)

/ IDCS DD DISP =(CLD, DELETE), UNIT $=2314, V G L=S E R=F I C I F S, D S N=R I C . I I$.WEEK

$/ / D C 6$ DD DISP=(CLD, DELETE), UNIT=ż14,VOL =SER=RICIRS,DSN=RIC.IERM.WEEK

/ /DD7 DD DISP=(CLD,DELETE), UNIT =2314,VOL=SER=RICIRS,DSN=RIC.WEEK.OLD

$1 / S O$ EXEC MOO,PACK=RICIRS

RENAME CSNAME=FIC.WEEK.NEW, VOL $=2314=R I C I R S, N E W N A M E=R I C \cdot W E E K . O L D$

$1 / 51$ EXEC PRCC=SORTO, TIME $=(1.30)$

I ISORTIN DO

/ /SCRTOUT DD UNIT=SCRTCH,DISF=(NEW.PASS), DSN=EETRANS,

/ $D \subset B=(R E C F M=F B, L R E C L=80, B L K S I Z E=3520)$,

SPACE $=(C Y L,(15,5) \cdot R L S E)$

/ /SORTWKOI DD UNIT 1 SCRTCH. SPACE $=(C Y L \cdot(20), . C C N T I G)$

/ SORTWKO2 DD UNIT $=S C R T C H, S P A C E=(C Y L,(20), . C C A T I G)$

$1 /$ SCRTWKO3 CC UNIT=SCRTCH.SPACE $=(C Y L,(20)$, , CONTIG)

ISYSIN DO

SORT FIELDS $=(62,9, C H, A, 75,1, C H, A, 74,1, C H, A)$

$1 / 152$ EXEC PGM=UFDAT2,REGION=76K.PARM= - ISASIZE $(4 \mathrm{~K}) \cdot, \operatorname{COND}=(9, L T), T I M E=2$

/ ISYSPRINT DD SYSOUT=A

$\angle / P L I C U M F$ DD SYSOUT=A

//TRANS CD DSN=EETRANS, UNIT =SCRTCH,DISF = (CLD,PASS)

$1 / M A S T E R 2$ DD DSN=RIC.WEEK. NEW, UNIT=2314, VCL=SER=RICIRS,

$1 / D I S P=(N E W, K E E P), S P A C E=(C Y L,(1,1))$,

$1 / D C B=(R E C F M=F B, L R E C L=80, B L K S I Z E=7280$, BUFNO=1)

$/ M A S T E R I D D$ DSN=RIC.WEEK. OLD,UNIT=2314, VOL =SER=RICIRS,

/ $D I S P=(C L C, K E E P), D C B=B U F N C=1$

$1 / W E E K$ DC *

//SI EXEC DGM=CITN,PARM=・ISA (6K) , REGION=72K,COND=( $9, L T)$

//PLIDUMP DO SYSOUT=A,DCB=(RECFM=VBA,LRECL=137, ELKS IZE=141)

$/ / S Y S P R I N T$ DD SYSOUT=A,DCE $=(R E C F M=V B A, L R E C L=137, E L K S I 2 E=141)$

//DATAIN DD DSN=RIC.WEEK.NEW,DISP=SHR, VOL=SER=RICIR S,UNII=2314, 


\section{Weekly Update for RICIRS (Continued)}

$1 / C C B=B U F N O=1$

/ C ITATN DO DSN=RIC.CIT,WEEK, DISP =(NEW, KEEP), UNIT=2314, VOL =SER=RICIFS,

1 , SPACE $=(C Y L,(E)), O C B=(C Y L C F L=0, C P T C C=U, C S O R G=I S)$

(/WCRD DC DSN=RIC,WORD, VOL=SER=SHCRT I, UNI T=2314,DISP= INEW,KEEP),

// $S P A C E=(C Y L,(15,5)), O C E=(R E C F M=F B, L R E C L=18, \theta L K S I Z E=7290)$

$/ / M S G P R T$ OD $S Y \subseteq C U T=A$

//SORTCD CD DSN=EE SORTCARD, UNIT=SCRTCH,DISP = (NE , FASS:, SFACE $=(T R K, 1)$

//S2 EXEC SYMSOFT, TRACKS $=500$, TIME=2

/ $S Y S I N$ CD DSN $=\varepsilon E S O R T C A R D, D I S P=(O L D, C E L E T E)$

/ /SCRTIN DD DSN=RIC.WORC,DISP=(OLD,KEEP), VOL=SER=SHCFTI,UNIT=2314,

11. $D C B=(R E C F M=F E, \angle R E C L=1 E, B L K S I Z E=7290)$

//SORTOUT DD DSN=RIC.SORT.WD, UNIT $=2314, V C L=S E R=S H C F T 1$, DI SP= (NEW, KEEF),

I CCB $=($ RECFM $=F E, L R E C L=18, B L K S I Z E=7290)$,

$1 /$ SPACE $=(C Y L,(15,5))$

$1 / S 4$ EXEC PGM $=$ TEFM,PARM $=$ I ISA $(16 \mathrm{~K}) \cdot$, REG ION $=72 \mathrm{~K}, C C N D=(5, L T)$

//SYSPRINT DD SYSOUT $=A, D C E=($ RECFM $=V B A, L R E C L=137, E L K S I \angle E=141)$

$1 / P L I D U M F$ DD $S Y S O U T=A, D C E=(R E C F M=V B A, L F E C L=137$, ELKS I $Z E=141)$

$1 / T E R M O U T$ DC CSA=RIC.TERN.WEEK. UNIT $=2314 \cdot V O L=S E R=F I C I F S$.

$1 / \mathrm{OISP}=(\mathrm{NEW}, \mathrm{KEEP})$,

/ $O C B=(C Y L O F L=0, O P T C D=U, D S O R G=I S), S P A C E=(C Y L,(3))$

/ IDCCWDRD DD DSA=RIC.SORTWD. DISP=(OLD, KEEP), UNIT=2314, VCL=SER=SHCFTI

$/ / M S G P R T$ DD SYSCL:T=A

I/EWOPRT DO SYSCLT=A

//SI EXEC PGM=PRINTEM,PARM= I ISASIZE (36K), NR , REGICN $=8 E K$

/ /ALTHOR DD $S Y \subseteq C L T=A$

//KEYWDRD DC SYSOUT=A

/ TEER OD DSN=FIC.TERM. WEEK, VOL =SER=FICIFS, UNIT T=2314, [I SP =SHR

//SE1 EXEC LIST,PACK $=R I C I R S, C O N C=(9, L T)$

LISTVTCC FORMAT, VOL $=2314=R I C I R S$

LISTPDS $V C L=2314=R I C I R S, D S N A M E=R I C \cdot P R O G$ 
Monthly Update for RICIRS

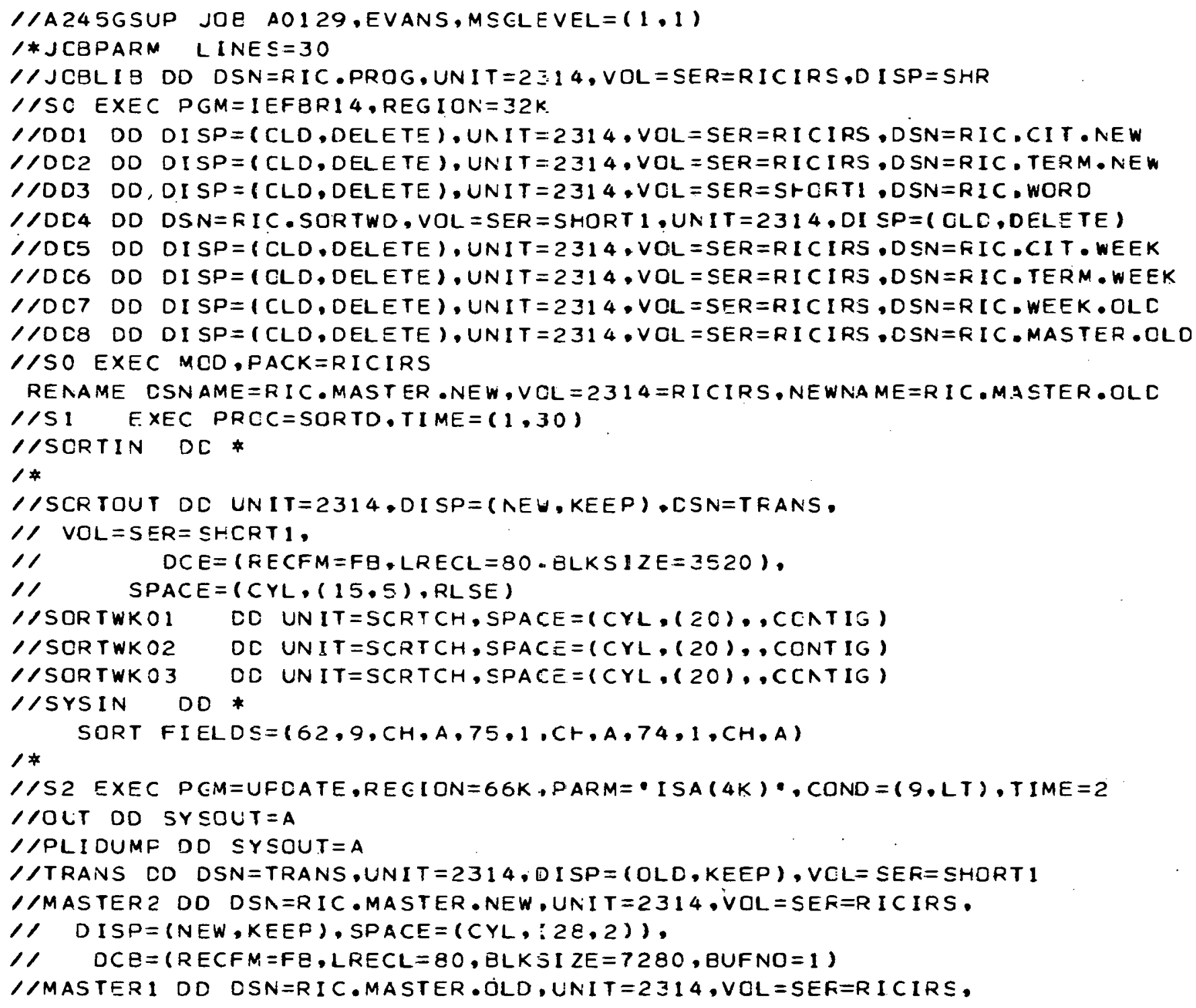




\section{Monthly Update for RICIRS (Continued)}

1/ DISF=(OLC, KEEP), OCB=EUFAO=1

/ WWEK DO DSN=RIC.WEEK. NEW, VOL=SER=RICIRS,UNIT $=2314, D I S P=S H R$

//SI EXEC PGM=CITN,PARM='ISA (6K), REGION=72K, COND=(, LT)

$/ / P L I D U M P$ DD $\subseteq Y \subseteq O U T=A \cdot D C B=(R E C F M=V B A \cdot L F E C L=137, E L K S I Z E=141)$

/ $/ S Y S P R I N T$ DD $S Y S O U T=A . D C B=(R E C F M=V B A . L R E C L=137 . E L K S I Z E=141)$

I/DATAIN DO OSN =RIC.MASTER.NEW, DISP=SHF, VOL =SEF=RICIRS,UNIT=2314,

$1 C C B=B U F N O=1$

$/ / C I T A T N$ DD DSN=RIC.CIT,NEW, DISP=(NEW,KEEP), UNIT $=2314, V O L=S E R=R I C I F S$,

$/ S P A C E=(C Y L \cdot(40)) \cdot D C B=(C Y L C F L=0 . O P T C C=U \cdot C S O R G=I S)$

/ /WORD DO DSN=RIC.WORD, VOL=SER=SHCRT I, UNIT=2314,DISP=(NEW,KEEP),

/ SPACE $=(C Y L \cdot(15,5)), D C E=(R E C F M=F B, L R E C L=18, B L K S I Z E=7290)$

$\angle / M S G P R T$ DD $S Y S C L T=A$

$/ / S O R T C D$ DD DSN=EESORTCARD, UNIT=SCRTCH,DISP=(NEW,FASS), SPACE=(TRK, 1$)$

//S2 EXEC SYMSCFT,TRACKS $=500, T I M E=2$

/ ISYSIN DO CSN=EESORTCARD.CISP=(CLD.CELETE)

//SORTIN DD CSN=RIC.WORD, OISP=(OLD,KEEP), VOL = SER=SHORI 1 UNIT=2314,

/ CC $Z=(F E C F M=F E \cdot L R E C L=18, B L K S I Z E=7290)$

/ ISOR TOUT DD OSN=RIC.SCRT MD, UNIT=2314, VCL=SER=SFCFT 1, CISP=(NEW, KEEF),

/ CCB $=$ (RECFM $=F E, L R E C L=18, B L K S I Z E=729 \mathrm{C})$.

$1 / S P A C E=(C Y L \cdot(15,5))$

$1 / S 4$ EXEC PGM=TERM,PARN=・ISA $(16 \mathrm{~K}) \cdot$, REGICA=72K, CONC $=(S, L T)$

I/SYSPRINT OD SYSOUT=A, DCB =(RECFM=VBA, LRECL=137, RLKSIZ $=141)$

I/PLIDUMP OD SYSOUT=A, DCB =(RECF $M=V B A, L F E C L=137, E L K S I Z E=141)$

/ ITERMOUT DD DSN=RIC.TERM.NEW,UNIT=2314, VCL =SER=RICIRS.

$\triangle C I S P=(N E W \cdot K E E P)$.

$1 / D C B=(C Y L C F L=C, O P T C D=U, D S O R G=I S), S P A C E=(C Y L,(10))$

$\angle O C C W O R D$ OD DSN=RIC.SORT WD, CISP=(OLD, KEEP), UNIT=2314, $/ O L=S E R=S H C F T 1$

$1 / M S G P R T$ DO $S Y \subseteq O U T=A$

$\angle / B W D P R T$ OD SYSCLT=A

$1 / S$ EXEC PGM=IEFER $14, C O N D=(9, L T), R E G I O N=32 K$

I/DCI DD DSN=RIC.WEEK. NEW.VOL=SER=RICIRS,UNIT=2314.DISP=(OLD,DELETE)

$1 / S 25$ EXEC PGM=DUM,PARM='ISASIZE(EK)', REGION=76K,COND=:9,LT)

I/PLIDUMF OD SYSOUT=A

I/CIT WK DD DSN=FIC.CIT, WEEK, VOL=SER=FICIRS,DISF =(NEW,KEEP),UNIT=2314,

I $O C B=(C S O R G=I S, O P T C D=U, C Y L O F L=0, B U F N C=1), S P A C E=(C Y L,: 1))$ 
/ I INOXWK DD DSN=RIC.TERM. WEEK, VOL =SER=RICIRS,OISF=(NEW,KEEP,$U N I T=2314$, $1 / D C Z=(C S O R G=I S, O P T C D=U, C Y L C F L=0 . B U F N C=1) \cdot S P A C E=(C Y L,(1))$

I/MASTER DO OSN $=R I C, W E E K$. NEW, CISP $=(N E W, K E E P), V O L=S E R=F I C I R S,(N I T=2314$, / $S P A C E=(T R K,(1,1)), D C B=(R E C F M=F E, L R E C L=80, B L K S I Z E=728 \mathrm{C})$

//SI EXEC PGM=PRINTEM,PARM= ISASIZE(36K), NR・,REGICN = ZEK

//ALTHOR DD SYSCLT=A

//KEYWORD DO SYSOUT=A

//TERM DD DSN=RIC.TERM,NEW,VOL=SER=RICIRS,UNIT=2314,DISP=SHR

IISEI

EXEC LIST, PACK $=$ RICIRS, CONC: $=(9, L T)$

LISTVTCC FORMAT, VOL $=2314=$ FICIRS

LI $\subseteq T D D S \quad V C L=2314=R I C I R S, D \subseteq N A M E=R I C$. PROG 


\section{Edited Key Word Index Card Printing JCL}

$1 / 8383 L M$ JOE AC129. MOON

//SI EXEC PGM=CARDPRT,PARN= ISA (4K) •,REGICN=36K

$/ / S T E P L I B$ DD DSN=RIC.PROG.VOL=SER=RICIFS.UNIT=2314, CISJ=SHR

/ IOUT DD SYSOUT $=A$

IIPLIDUMF DC SYSGUT=A

IIIN DO *

EINARY

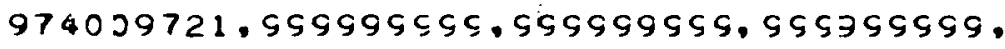
974039721

CRY STAL-STRUC

ETCHING

9730 ग \&80

$9730 \Omega 9880$

GDFEO 3

LAFEO

$9730 \approx 9 \sec .974009720$

LAT TI CE - PAR AM

IPRE PARATI ON

$40 \supset 9720$

9730.29880

9730.59880 .974009720 .974009721

SINGLE-CRYSTAL

$973059880.97400972 \mathrm{C} .974005721$

973029880.974009720 .974005721

SYSTEM

$9740 \supset 9721$

TBFEO3

$9730 \supset \varsigma \varepsilon \varepsilon C, 974005720,974005721$ 


\section{DUST Update JCL}

$1 / 8383 L M 2$ JOB AC129. MOCN, MSGLEVEL $=(1,1)$

*JCBPARN LINES $=30$

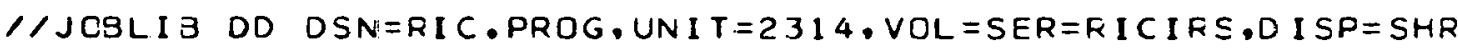

$1 / S O$ EXEC PGM=IEFBR 14,REGION=32K

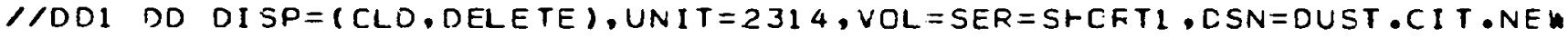

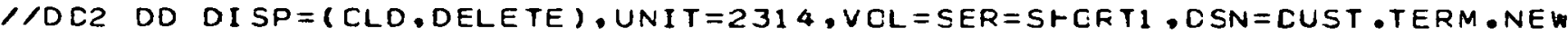

$1 / D C 3$ DD $D I S P=(C L D, D E L E T E), U N I T=2314, V C L=S E R=S H O F T 1, O S N=F I C \cdot$ WORD

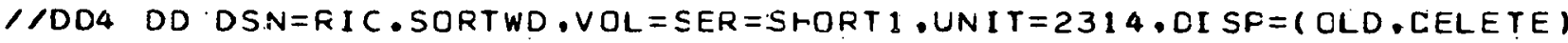

/ DOC5 DD DISP $=(C L D, D E L E T E), U N I T=2314, V O L=S E R=S H C F T 1, O S N=D U S T \cdot C I T \cdot W E E K$

$/ / D C 6$ DD $O I S P=(C L D, D E L E T E), U N I T=2314, V O L=S E R=S H C R T 1, C S N=C U S T$.TERN,WEEK

$1 / D O 7$ DD OI SP = (CLD, DELETE ), UNIT $=2314, \mathrm{VOL}=S E R=S H C R T 1, D S N=C U S T, W E E K, O L D$

$1 / D O S$ DO CSN=DUST.MASTER.NEW,UNIT=2314, $\mathrm{VCL}=S E R=S H C R T 1, D I S P=(C L D, C E L E T E)$

//S 1 EXEC PRCC=SORTD, TIME $=(1,30)$

IISORTIN DO*

/*

/ISCR TOUT DD UNIT =SCRTCF, DISP = (NEW, PASS $1, D S N=E E T R A N S$,

I/ $\quad D C B=(R E C F M=F B, L R E C L=80, B L K S I Z E=3520)$,

$1 / \quad S P A C E=(C Y L,(15,5), R L S E)$

//SCRTWKO1 CD UNIT=SCRTCH,SPACE $=(C Y L, 120)$, CCNTIG $)$

//SORTWKO2 DC UNIT=SCRTCH,SPACE $=(C Y L, I 20), . C C N T I G)$

//SCRTWKO3 CC UNIT=SCRTCH,SPACE $=(C Y L, 120)$, ,CCNTIG $)$

IISYSIN DD *

SORT FI ELDS $=(52,9, C H, A, 75,1,21, A, 74,1, \mathrm{CH}, \mathrm{A})$

$1 *$

I/S: EXEC PGM=IEEGENER

I/SYSPRINT DD SYSOUT=A

//SYSIN CD DUMMY

//SYSUT 1 DD UNIT $=(2400$, ,DEFEF $), D I S P=(O L E, K E E P), \angle A B E L=(1, S L)$,

$1 / D S N=D U S T \cdot M A S T E R \cdot N E W \cdot V C L=S E R=D U S T C 1$

/ /SYSUT2 DD DSN=DUST, MASTER. OLD,UNIT=23:4, VOL=SEF=SFORT 1 ,

$1 / \mathrm{DISP}=(N E W, K E E P), \operatorname{SPACE}=(C Y L,(2,2))$

$1 / S 2$ EXEC PGM=UPDAT2,REGION=76K,PARM= ISASIZE (4K) , COND $=(9, L T), T I M E=2$

//SYSPRINT DD $S Y S D U T=A$

I/PLIDUMP DD $S Y \subseteq O U T=A$

I/TRANS CD CSN=EETRANS, UNIT $=S C R T C H, D I S P=(C L D, P A S S)$ 
/ MASTER 2 DD CSN=DUST.MASTER. NEW, UNIT $=2314, V C L=S E R=S H C R T 1$,

$1 / D I S P=(N E W, K E E P), S P A C E=(C Y L,(2,2))$,

/ $D C B=(R E C F M=F B, L R E C L=80$, ELKSI $Z E=7280,8 U F N O=1)$

$/ / M A S T E R I$ DD OSN=DUST.MASTER,ULD, UNIT= $T 314, V C L=S E R=S H E R T 1 . D I S P=S H R$.

1/ $C C B=8 U F N C=1$

$1 / W E E K$ DC

/ /SI EXEC PGM=CITN,PARM=1 ISA (6K), REGICN=72K, COND=(,$i T)$

$/ / P L I O U M P$ DO $S Y \subseteq O U T=A, D C B=(R E C F M=V B A, L R E C L=137$. ELKSIZE=141)

//SYSPRINT DD SYSOUT=A, DCB =(RECFM $=V B A, L R E C L=137, B L K S I I E=141)$

$/ / D A T A I N$ DO DSN=DUST.MASTER. NEW, DISP=SHF, VOL =SEF=SHORTI.UNIT=2314.

I/ $C C B=B U F N C=1$

$/ / C I T A T N$ DD DSA=DUST.CIT.NEW.DISP=(NEW,KEEP), LAIT=2314, VGL=SER=SHCFT1,

$, S P A C E=(C Y L \cdot(4)), D C B=(C Y L O F L=0, C P T C D=U, C S O R G=I S)$

$/ / W O R D$ DD DSN=RIC.WORD, VOL=SER= SHCRT1, LNIT=2314,DISP=:NEW,KEEP),

$1 / S P A C E=(C Y L,(15,5)), D C B=(R E C F M=F B, L F E C L=18, E L K S I Z E=7290)$

$/ / M S G P R T$ DD $S Y S C L T=A$

//SORTCD OD DSN=EESORTCAPD, UNIT =SCRTCH,DISP=(NEW,FASS:, SPACE=(TRK, 1)

$1 / S 2$ EXEC SYMSOFT, TRACKS=500, TIME=2

IISYSIN OD DSN=EESORTCARD, CISP=(OLD, CELETE)

/ ISORTIN DD CSA=RIC.WORO.DISP = (OLD,KEEP), VOL=SEF=SHCPT1.UNIT=2314.

/ $D C B=($ FECFM $=F E, L R E C L=18, B L K S I Z E=7290)$

/ /SCRTOUT DD DSN=RIC.SORTWD. UNIT=2314, VCL=SER=SHOFT 1, OISP=(NEW, KEEP).

$1 / D C B=(R E C F M=F E, L R E C L=1 \varepsilon, B L K S I Z E=729 \mathrm{C})$.

I/ SPACE $=(C Y L,(15,5))$

$1 / 54$ EXEC PEM=TERM,PARM='ISA $(16 \mathrm{~K}) \cdot, R E G I O N=72 \mathrm{~K}, C C N C=(\mathrm{S}, \mathrm{LT})$

$1 / S Y S P R I N T$ DD SYSOUT=A. DCB =(RECFM=VBA, LRECL=137, ELKSI $\angle E=141)$

,$/ P L I D U M P D D$ SYSOUT=A.DCE=(RECFM=VBA,LRECL=137. BLKSIZE=141)

$/ / T E R M O U T$ DC CSN=DUST.TERM.NEW, UNIT=2314, VCL $=S E F=S H C R T 1$.

$1 / D I S P=(N E W, K E E P)$,

/ $D C B=(C Y L C F L=0 . O P T C D=U, D S O R G=I S), S P A C E=(C Y L,(2))$

$/ / D C C W O R D$ DD DSA=RIC.SORTWD, DISP=(OLD,KEEP), UNIT=2314,VOL=SER=SHCRTI

$/ / M S G P R T$ DD SYSCUT=A

$\angle / B W D P R T$ DD $S Y S C U T=A$

/IS EXEC PGM=IEFBRI4,CCND=(9,LT), REGION=32K

I/DDI OD DSN=DL ST. WEEK. NE V, VOL=SER=SHOFT 1, UNIT=2314.DISP=(OLD.DELETE) 
$1 /$ S25 EXEC PGM=CUM,PARM= ISASIZE (6K) * FEGION=76K, COND=(S,LT:

$/ / C I T W K$ DD DSN=OUST.CIT.WEEK, VOL=SER=SHCFT1,DISP=(NEW,KEEP),UNIT=2314,

I/ CCB $=($ CSORG =IS, OPTCD $=U, C Y L O F L=0, B U F N C=1)$, SPACE $=(C Y L,(1)$ )

/ I NDXWK DD DSA=DUST .TERM .WEEK, VOL=SEF=SHOFT 1, DISP $=(N E W, K E E P)$.

$1 /$ UNIT $=2314$.

I $C C B=(C S O R G=1 S, O P T C D=U, C Y L C F L=C, B U F N C=1), S P A C E=(C Y L,(1)$

IIMASTER DD DSN=DUST. WEEK.NEW,DISP=(NEW,KEEP), VOL=SER=SHORTI,UNIT=2314.

/ SPACE $=(T R K,(1,1)), D C B=(R E C F M=F E, L R E C L=80, B L K S I Z E=728 C)$

$/ / P L I D U M F$ DC $S Y S C U T=A$

/ISI EXEC PGM=PRINTEM,PARM= I ISASIZE (35K) . NR , RECICN=86K

$/ / A \cup T H O R$ DD SYSCUT=A

I/KEYMORD DC SYSCUTI=A

$1 / T E R M$ DD DSN=DLST.TERM.NEW, VOL $=S E R=S-C F T 1, U N I T=2314, D I S P=S+R$

/ ISZ EXEC PGM IEECOPY

/ SSYSPRINT DD SYSOUT=A

I/SYSUTI DO DSN=RIC.PROG, VOL=SER=RICIRS, UAIT=2314, II ISP=SHR

/ ISYSUT2 DO CSN=CUST.PROG, UNIT=2314, VDL=SER=SHORTI.DISP=(NEW,KEEP).

$1 /$ SPACE $=(T R K \cdot(\varepsilon \cdot 2 \cdot 2))$

I/SYSIN DD *

COPY OUTDD=SYSLT2, INDD=SYSUT 1

SELECT MEMBER = (SIGAR, KEYPRT, AUTHPRT) 
$\angle / B 3830 U S T$ JOB AO129,VERKACE

$/ / J C B L I B$ OD DSN=DUST .PROG, VOL=SER=SHORT I,UNIT=2314. OISP=SHR

I/SI EXEC PGM=SIGAR,PARM= ISA (1IEK) , REGICN=220K

/ ISYSPRINT DD SYSOUT $=A, D C B=(R E C F M=V B A, L R E C L=137, E L K S I Z E=141)$

$/ / C I T W K$ CO UNIT $=2314$, DISP=SHR,DSN=DUST •CIT . WEEK .

16 $D C B=\{C S C R G=I S, B U F N C=1\}, V O L=S E F=S H O R T$ I

$/ /$ IND XWK DD UNIT=2314.DISP=SHR,DSN=DUST . TERM • WEEK,

$1: C C B=(C S D R G=I S, B U F N O=1), V O L=S E R=S H O R T 1$

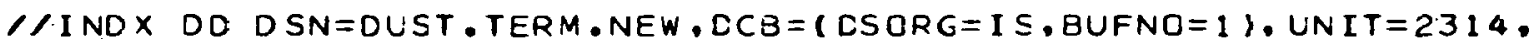

/ $V O L=S E R=S H O R T 1, D I S P=S H R$

I/CITATN DD DSN=DUST.CIT.NEW,OCB=(DSCRG=IS, BUFND=1).UNIT=2314.

/ $V O L=S E R=S H C R T 1, D I S P=S H F$

$\angle / L I B R P T R$ DC SYSOUT=A

I U SERPRT DC SYSCUT=A

$/ / P L I D U M P$ JD $\subseteq Y \subseteq O U T=A, D C B=(R E C F M=V B A, L F E C L=137, E L K S I Z E=141 . E U F N O=1)$

IIREQUEST DC *

$12000200 \mathrm{C} \quad 1$ XREF

FIRE * CONTFOL * ( GRAIN + AGRICULTURAL + SUGAR + FLCUR +.STARCH । $\neg$ EXFLOSION

ॠ9999KBE - 1

//AUTHOR DJ DSN=EEAUTH, OISP=(NEW,PASS), VCL=SER=SHORT1,UNIT=2314,

/ $D C B=(R E C F M=F E, L R E C L=24, B L K S I Z E=18.00, B L F N O=1)$,

$1 /$ SPACE $=(T R K,(1,1)$

I/KEYWORD JD DSN=EEKEY,DISP= (NEW,FASS), UNIT=SCRTCH,

/ CCB $=($ RECFM $=F E, L R E C L=19, B L K S I Z E=18 C 5$, BUFNO=1),

$1 /$ SPACE $=(T R K,(3.2))$

/ IS 3 EXEC PGM=KEYPRT,PARM= I ISA ( 04K), NR・,REGION=48K

//SYSPRINT CD SYSOUT=A

$/ / D L T$ DD SYSOLT=A

//OUTCARE DE CUMMY

$/ / S O R T I N$ DD CSN=EEKEY, OISP= (OLD, DELETE). UNIT=SCRTCH,

/ $D C B=(R E E F M=F E, L R E C L=19, B L K S I Z E=1805)$

//SCRTOUT DO CSN=EETEMP 2. DISP=(NEW, DELETE), UNIT=SCRTCH,

// SPACE $=(\mathrm{IRK},(3,2)), D C B=(R E C F M=F E, L R E C L=19, B L K S I Z E=1805)$

/ $/ S Y S O U T$ DD SYSCUT=A 
DUST Retrieva1 Program with Key Word Indexes and No Key Word Index Carc Output (Continued)

/ SCRTLIE DO DISF=SHR, DSN=SYSI, SOFTLIE

//SORTWKO1 DD UNIT=SCRTCH, SPACE $=(T R K,(30),$, CCNTIG)

/ ISCRTWKOZ CC UNIT=SCRTCH.SPACE $=(T R K,(3 C)$, ,CCATIG)

//SORTWKO3 DD UNIT $=$ SCRTCH, SPACE $=(T R K,(30),$, CONTIG $)$ 
//DLSTDUMP JOE $\triangle 0129$, MOON, MSGLEVEL $=(1,1)$

$/ / J O B L I B$ DD DSN=RIC.PRCG, UNIT=2314, VOL =SER=RICIRS,DISP=SHR

//SI EXEC MOO,PACK=SHORT1

SCRATCH VOL $=2314=$ SHORT1, OSNAME = CUST . CIT . WEEK

SCRATCH VOL $=2314=$ SHORT 1 , DSNAME = DUST . TERM.WEEK

SCRATCH VOL $=2314=$ SHORT 1 , DSNAME = CUST . WEEK. NEW

SCRATCH VOL $=2314=$ SHORT 1, DSAAME = CUST. PROG

SCRATCH VOL $=2314=$ SHORT 1, DSNAME =CUST . CIT.NEW

SCRA TCH VOL $=2314=$ SHORT 1, OSA AME =CUST. TERM . NEW

//LCADI EXEC PGM=IEGISAM, PAFN=LOAD

I/SYSPRINT CC $\subseteq Y \subseteq O U T=A$

//SYSUT 1 DD UNIT=(TAPE., OEFER), VOL=SER =DUSTO 1, DISP= (OLD,PASS),

// $L A B E L=(2, S L), D C B=(R E C F M=F E, L R E C L=80, B L K S I Z E=640)$.

$1 /$ DSN=CUST, CIT .NEW

/ $/ S Y S U T 2$ DO UNIT $=2314, V O L=S E R=S H O F T 1, D I S F=(N E W, K E E P), E C B=(C S O R G=I S)$,

/ $/$ SPACE $=(C Y L,(5,5)), D S N=D U S T$. CIT .NEW

/ UUNLOAD2 EXEC FGM=IEBISAM,PAFM=LCAD

/ ISYSPRINT DO $S Y S O U T=A$

//SYSUT1 OD UNIT=(TAPE, , DEFER ), VOL=SER=DUSTO1, DISP=(CLD, PASS ),

1/. $L A B E L=(3, S L), D C B=(R E C F M=F E, L R E C L=8 \mathrm{C}$, $B L K S I Z E=640)$,

$1 /$ DSN=OUST . TERM. NEW

//SYSUT2 COD UNIT=2314,VOL=SER=SHORT 1, CISP $=(N E W \cdot K E E P), D C B=(D S O R G=I S)$, / SPACE $=(C Y L,(E, 5)), D S N=D U S T$.TERM.NEW

$1 / S 25$ EXEC PGM=DUM,PARM $=\cdot$ ISASIZE $(6 K) \cdot, R E G I O N=7 E K, C O N D=(G, L T)$

$\angle$ PLIDUMF DC SYSCUT=A

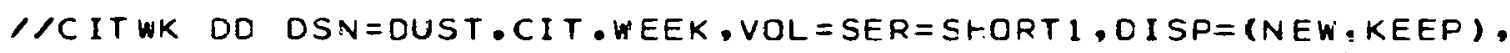

/ $D C B=I R E C F M=V E, L R E C L=\$ 12$, ELKSIZE=916, CSORG=IS, KEYLEN=4,RKP=8,

1 , OP TCD $=U, B U F N C=1, C Y L O F L=0), S P A C E=(C Y L,(1,1)), U N I T=2314$

$1 /$ INDXWK DD DSN=CUST.TERN. $W E E K, V O L=S E R=S H C R T 1, O I S P=(N E W, K E E P)$,

$1 /$ UNIT $=2314$, DCE $=(R E C F M=V B, L R E C L=7220$, ELKSIZE $=7233, K E Y L E N=15, R K P=5$,

I DSORG = I $S, O P T C D=U, C Y L O F L=0, B U F N C=1), S F A C E=(C Y L,(1,1:)$

$/ / M A S T E R$ CD DSN=DUST . WEEK. NEW, DISP=(NEW, KEEP ), VCL=SEF=SHCFT $1, U N I T=2314$,

$1 / S P A C E=(T R K \cdot(1,1)), D C B=(R E C F M=F E, L R E C L=80, B L K S I Z E=7280)$

//S2 EXEC PGM=IEQCOPY

I/SYSPRIAT DO SYSOUT=A 
Recreate DUST Files and Programs on SHORT1 (Continued)

//SYSUT1 DO DSN=RIC.PROS, VCL =SER=FICIRS, UNIT $=2314,0$ ISP=SHR

//SYSUT 2 DD DSN=OUST,PROG,UNIT=2314,VOL=SER=SHORT1, DISP=(NEW,KEEF),

// $S P A C E=(T R K \cdot(\varepsilon, 2,2))$

I/SYSIN DD *

COFY OUTDD=SYSUT2, INDD=SYSUT 1

SELECT MEMBER = ( $I$ I GAR, KEYPRT, AUTHPRT ) 
VIII. Appendix B: RICIRS Flowchart

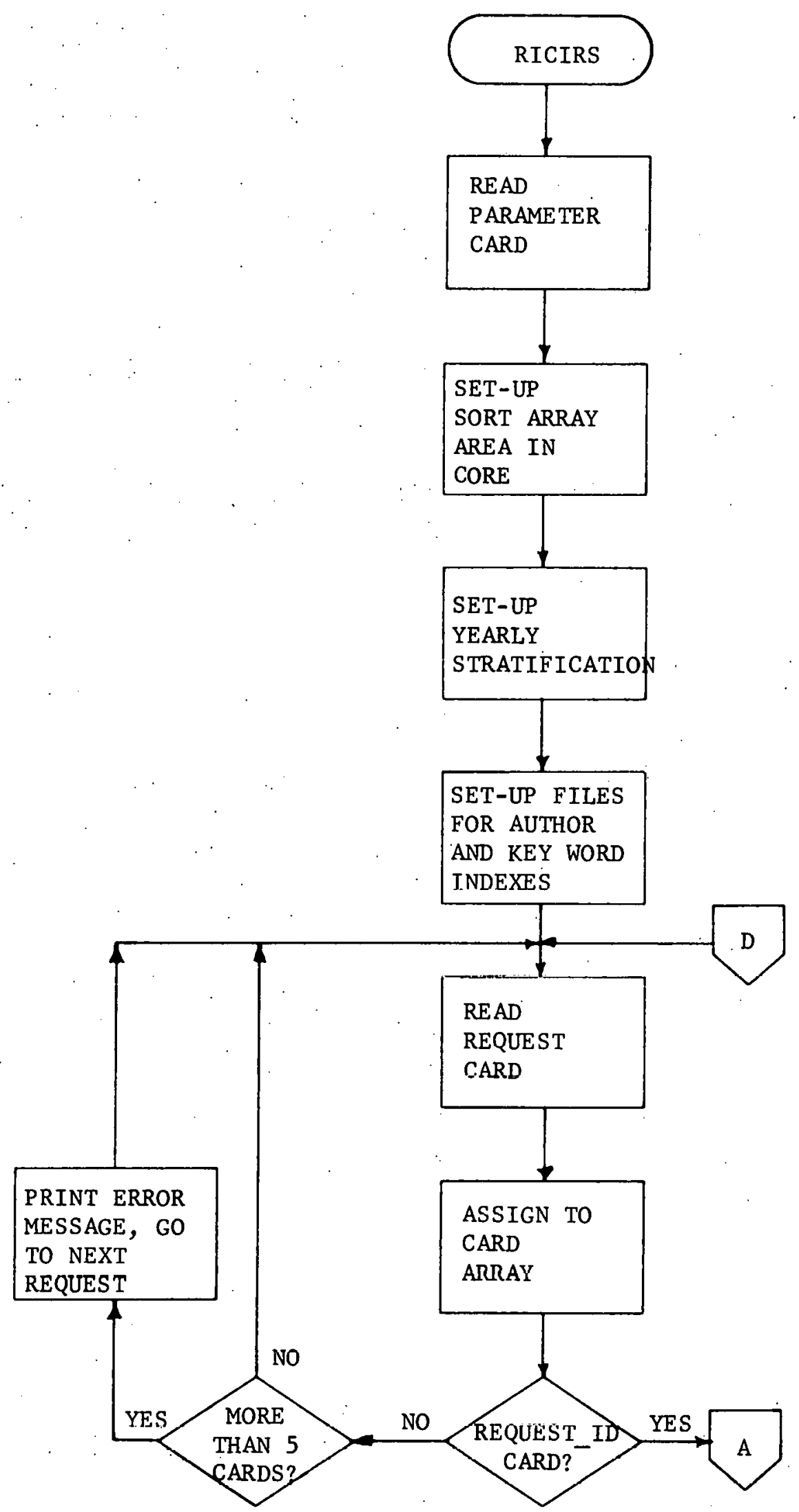




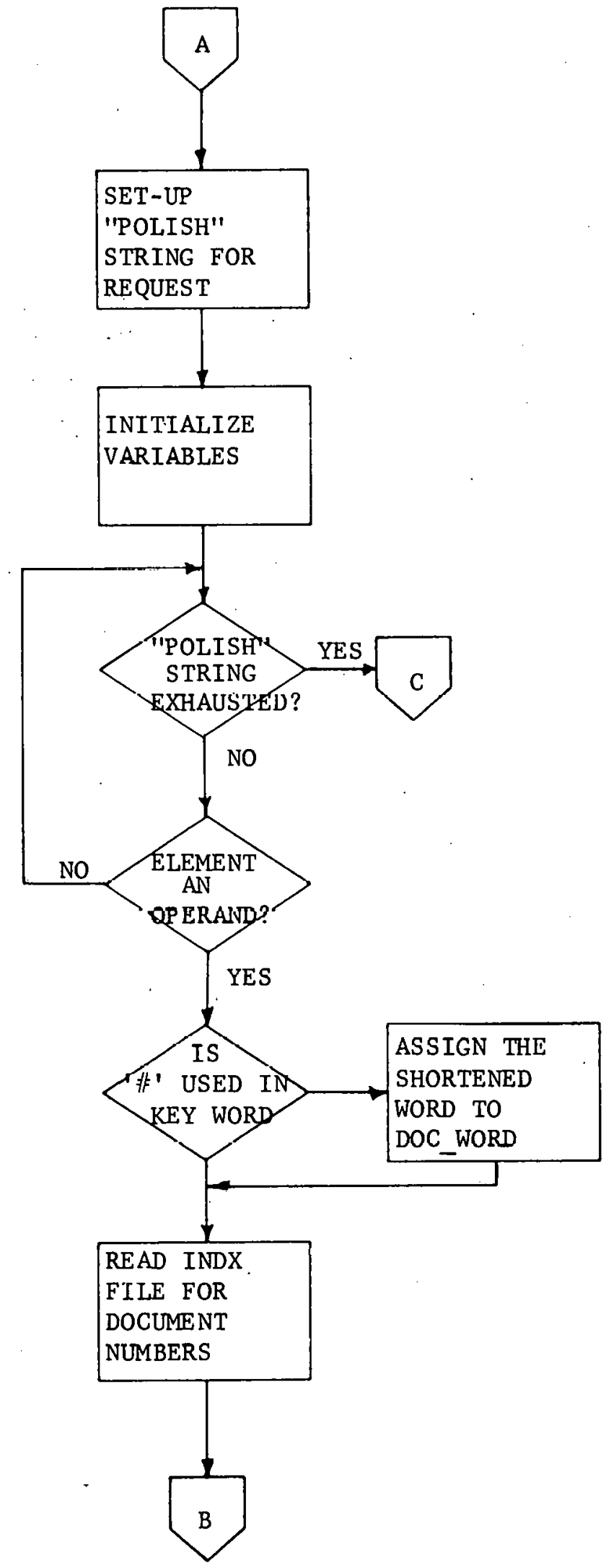

RICIRS Flowchart (Continued). 


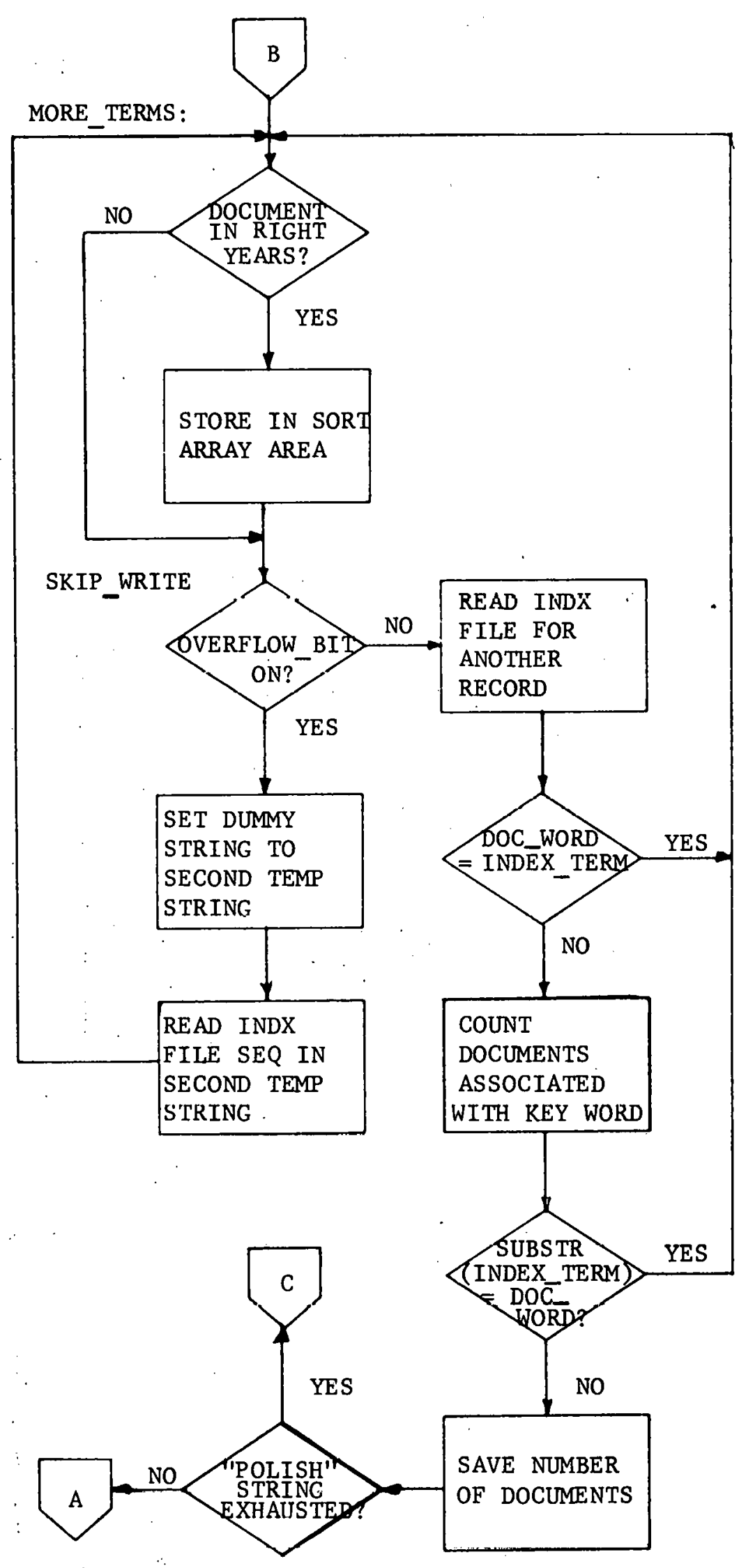

RICIRS Flowchart (Continued). 


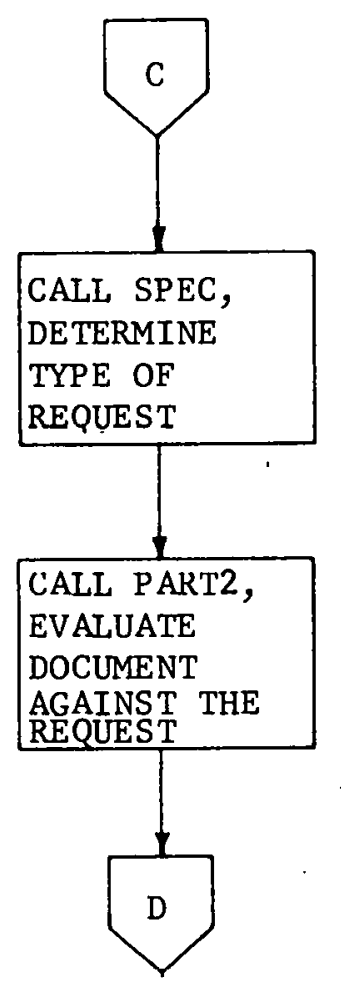

RICIRS Flowchart (Continued). 


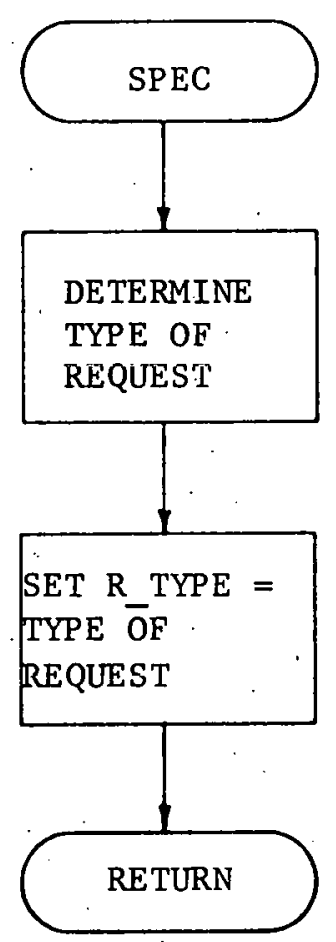

RICIRS F lowchart (Continued). 


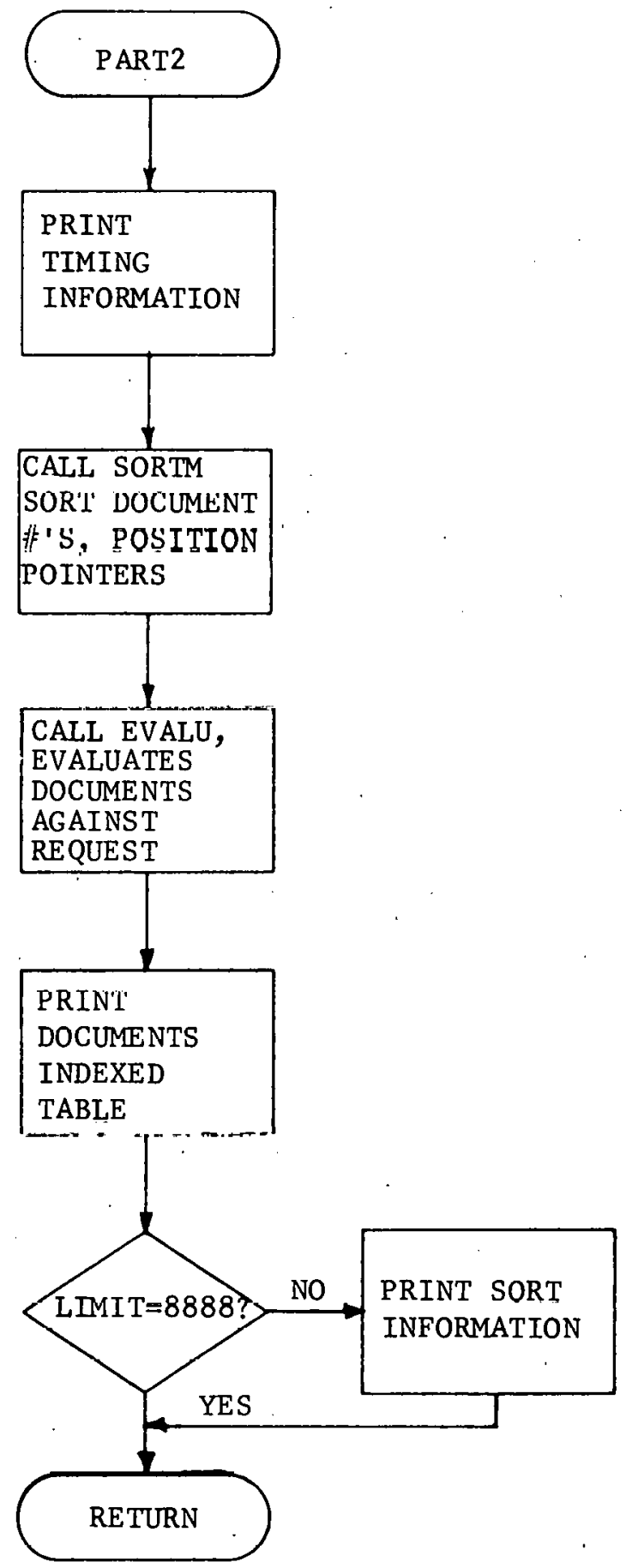

RICIRS Flowchart (Continued). 


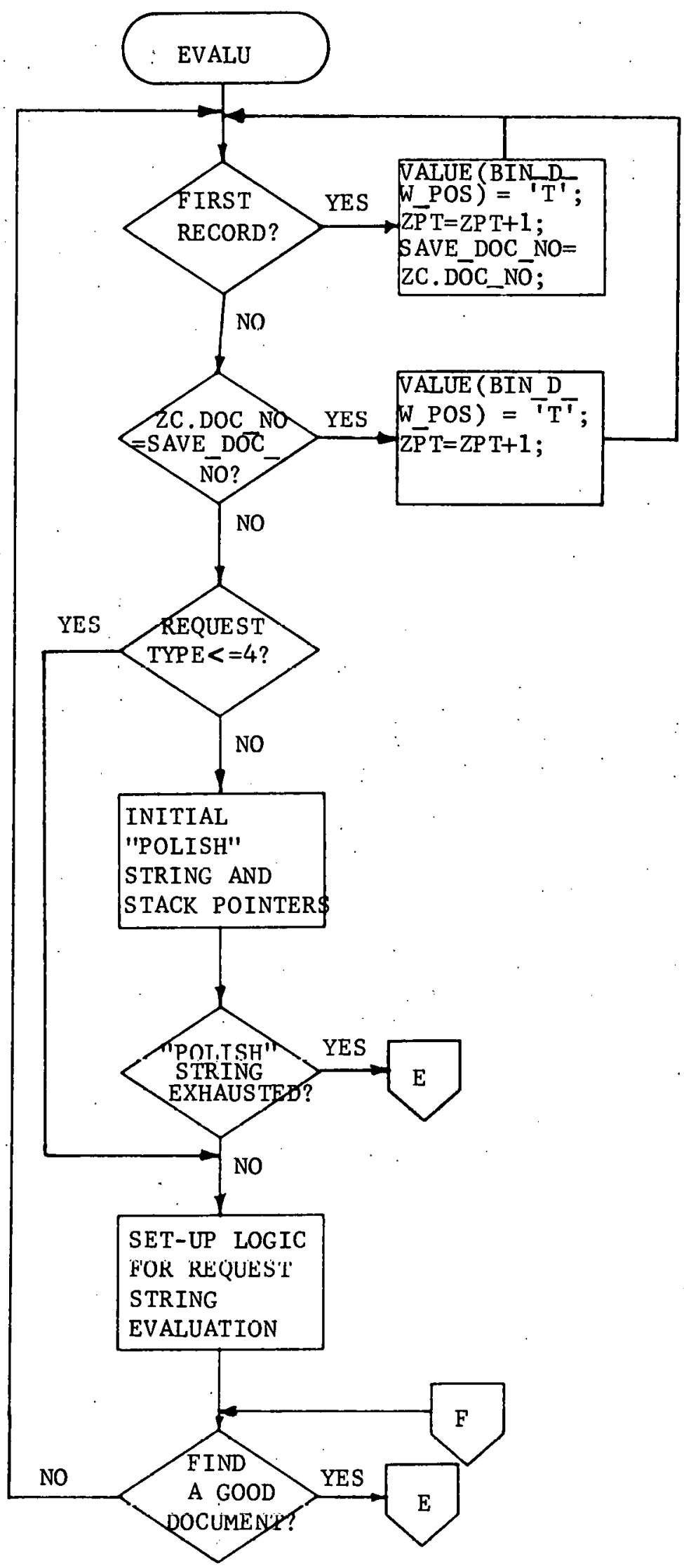

RICIRS Flowchart (Continued). 


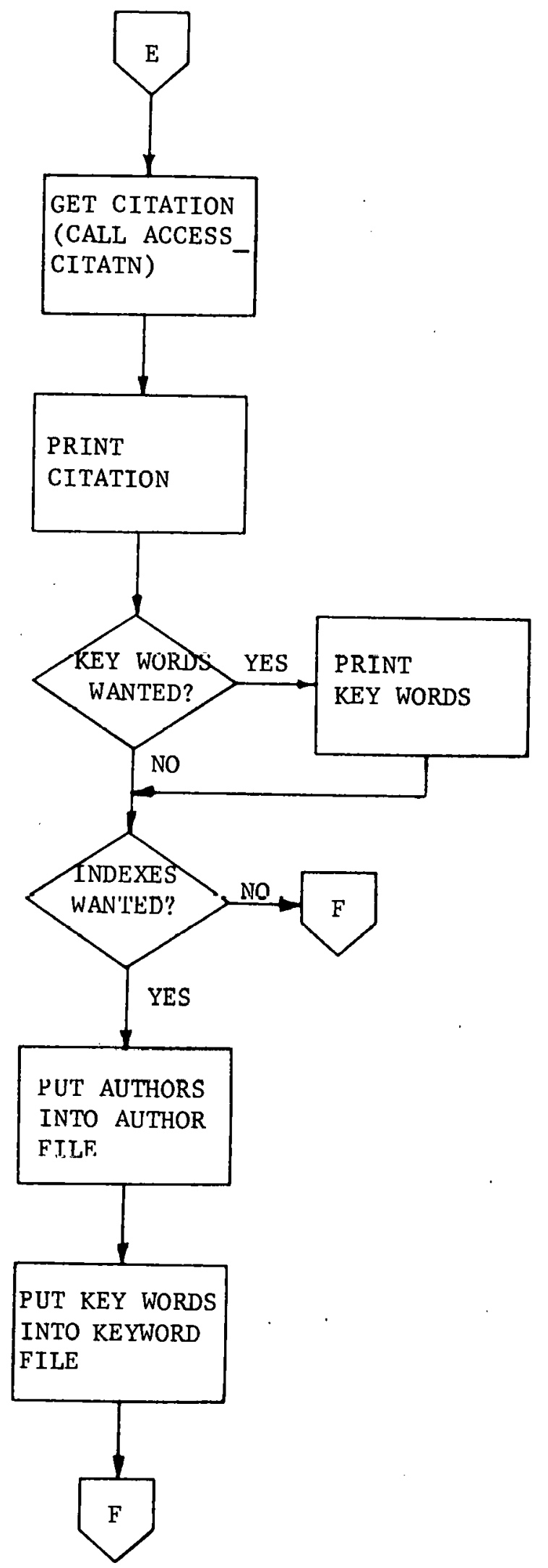

RICIRS Flowchart (Continued). 